\title{
TRAUMA PSÍQUICO Y TRASTORNO DE ESTRÉS POST TRAUMÁTICO. JUDITH HERMAN: ABORDAJE TERAPÉUTICO*
}

Carmen Morales Miranda*

\begin{abstract}
Resumen
Las personas que sufren estrés post traumático suelen ser renuentes a pedir ayuda de cualquier tipo, con excepción de la psicoterapia. La recuperación estará basada en el empoderamiento del sobreviviente y en la curación de sus nuevas conexiones, puesto que esa recuperación sólo puede darse dentro del contexto de las relaciones y no en aislamiento. Sus renovadas conexiones con el medio le permitirán recrear las facultades psicológicas dañadas o deformadas por la experiencia traumática y recuperar sus capacidades básicas como confianza, autonomía, iniciativa, competencia, identidad e intimidad.
\end{abstract}

Palabras clave: trastorno de estrés post traumático, recuperación.

\begin{abstract}
People who suffer from post traumatic stress are usually reluctant to ask for any kind of help, except for psychotherapy. Recovery will be based on the survivor empowerment and the healing of his new connections, since this recovery can only happen in the context of relationships and not in isolation. His renewed connections with the medium will allow him to recreate the damaged or deformed psychological faculties caused by traumatic experience and to recover his basic capacities such as trust, autonomy, initiative, competence, identity and intimacy.
\end{abstract}

Key words: post traumatic stress disorder, recovery.

* El artículo está basado en el libro de la autora, Trauma psíquico y trastorno de estrés post-traumático, 2007, Lima, Perú: Universidad Femenina del Sagrado Corazón.

* * Psicóloga, Psicoterapeuta. Magíster y Doctora en Psicología, UNIFÉ. Coordinadora del ProgramaAcadémico de Maestría y Doctorado en Psicología, UNIFÉ. cmdei@speedy.com.pe 
En 1999, en el $16^{\text {th }}$ Annual Meeting de la ISTSS (International Society for Traumatic Stress Studies), fueron presentados los lineamientos para el tratamiento del Trastorno por Estrés Post Traumático, en los cuales se establecieron estándares sobre la base de las investigaciones realizadas hasta ese momento.

En su libro "Trauma y Recuperación", Judith Herman plantea 5 etapas en el proceso de recuperación del paciente víctima de TEPT:

1. Una relación que cura.

2. Seguridad

3 Recuerdo y lamento

4. Reconexión

5. Comunidad

A continuación, presentaremos las etapas:

\section{Primera etapa: Una relación que cura}

Judith Herman plantea un punto fundamental, la relación terapéutica es única en varios aspectos y su propósito es promover la recuperación del paciente, el terapeuta se convierte en un aliado que pone todos los recursos de su conocimiento, habilidad y experiencia a disposición del paciente.

El terapeuta debe respetar la autonomía del paciente y mantenerse neutral, esto significa que no debe tomar posición frente los conflictos internos del paciente o tratar de dirigir sus decisiones.

La alianza terapéutica debe constituirse cuidadosamente y con el esfuerzo de ambos, la terapia requiere de una relación de colaboración y trabajo en la cual ambas partes actúan sobre la misma base de su implícita confidencia, en el valor y la eficacia de la persuasión más que en la coerción, en las ideas más que en la fuerza, en la mutualidad más que en el control autoritario.

El trauma daña la habilidad del paciente para ingresar en una relación confiable, tiene también un impacto indirecto pero poderoso en el terapeuta. Como resultado, tanto el paciente como el terapeuta tendrán dificultades predecibles antes de llegar a una alianza de trabajo. Estas dificultades deben ser comprendidas y anticipadas desde el principio.

\section{Segunda etapa: Seguridad}

Debido a que la recuperación ocurre en etapas, el tratamiento debe ser apropiado para cada una. Una forma de terapia que puede ser útil para un paciente en una etapa, puede ser de muy poca ayuda o incluso dañina para el mismo paciente en otra. En cada etapa de la recuperación, el tratamiento comprehensivo debe dirigir las características biológicas, psicológicas y los componentes sociales del desorden. No existe ninguna "bola mágica" eficaz para el tratamiento del síndrome traumático.

Los síndromes traumáticos no pueden ser tratados apropiadamente si no son diagnosticados. La primera tarea del terapeuta es conducir una evaluación diagnóstica cabal e informada. Con pacientes que han sufrido un trauma agudo reciente, el diagnóstico, por lo general, es completamente directo. En situaciones tan claras, la información detallada concerniente a las reacciones post traumáticas son invalorables para el paciente y su familia o amigos. Si el paciente está preparado para los síntomas de sobre excitación, intrusión y adormecimiento, estará mucho menos asustado cuando ocurran. Si él y aquellos que tiene cerca, están preparados para las interrupciones en la relación que seguirán a la experiencia traumática, serán mucho más capaces de tolerarlas y aceptarlas en su momento. En cambio, los pacientes que han sufrido un trauma prolongado y repetitivo no permiten un diagnóstico tan directo y suelen disfrazar sus síntomas de estrés post traumático.

Inicialmente, el paciente puede quejarse sólo de un síntoma físico o de insomnio o ansiedad crónica o de depresión intratable o de relaciones problemáticas. Usualmente, se utilizan cuestionarios explícitos para determinar si el paciente vive actualmente con temor a la violencia de alguien o ha vivido en ese estado en algún momento en el pasado.

Cuando el paciente ha sido sujeto de un abuso prolongado en su niñez, la tarea de emitir el diagnóstico se vuelve muy complicada. El paciente puede no tener un recuerdo completo de la historia traumática y puede negar inicialmente dicha historia, aún con preguntas directas y cuidadosas. Es más común que el paciente recuerde por lo menos alguna parte de su historia traumática, pero no hace ninguna conexión entre el abuso del pasado y sus problemas psicológicos del presente. Este es quizás el más difícil de todos los diagnósticos en casos de desorden disociado severo. 
La persona traumatizada suele sentirse aliviada con el mero hecho de conocer el nombre real de su condición, averiguar su diagnóstico significa el comienzo del proceso de superación. Al no estar aprisionada por el mundo silencioso del trauma, descubre que hay un lenguaje para su experiencia, se da cuenta de que no está sola, que hay otras personas que han sufrido lo que ella sufre y descubre más adelante que no está loca, que los síndromes traumáticos son respuestas humanas normales a circunstancias extremas y que no está condenada a sufrir esta condición indefinidamente, que puede esperar una recuperación como tantas otras personas que ya han salido del pozo.

$1^{\circ}$ Con los sobrevivientes de traumas prolongados y repetidos es particularmente importante indicar la complejidad del desorden post traumático y explicar las deformaciones de la personalidad que ocurren bajo el dominio del trauma. Mientras que los pacientes con un desorden de estrés post traumático simple temen estar perdiendo la razón, los que sufren un desorden complejo usualmente sienten haberse perdido ellos mismos.

El trauma le roba a la víctima el sentido de poder y control, y la vía principal para su recuperación es restablecerle ambas capacidades y con ello, su seguridad. Esta tarea precede a todas las demás, ya que ningún otro trabajo terapéutico puede tener éxito si la seguridad del sobreviviente no ha sido adecuadamente restablecida. Esta etapa inicial puede durar días y hasta semanas en casos de traumas agudos o meses y hasta años si se trata de sobrevivientes de abuso crónico.

El trabajo de la primera etapa de recuperación se vuelve cada vez más complicado en proporción a la severidad, duración y comienzo temprano del abuso. Los sobrevivientes se sienten inseguros con relación a otra gente y perciben que sus emociones y pensamientos se les descontrolan. Las estrategias de la terapia deben enfocarse sobre las preocupaciones de seguridad del paciente en todos estos dominios. El tratamiento de la fisioneurosis del desorden del estrés post traumático incluye el uso de medicamentos para reducir la reactivación y la sobre excitación y de técnicas conductistas como relajación o ejercicios para manejar el estrés, así como el de estrategias cognitivas y de conducta que incluyen el reconocimiento y el nombramiento de los síntomas, el uso diario de secuencias para anotar los síntomas y las respuestas de adaptación, la definición de tareas "de casa» manejables y el desarrollo de planes de seguridad concretos. La destrucción de los vínculos que sobreviene con el desorden debe ser manejada mediante estrategias interpersonales, entre las que se incluyen el desarrollo gradual de una relación confiable en la psicoterapia.

La alienación social del desorden debe ser dirigida a través de estrategias sociales, éstas incluyen la movilización de los sistemas naturales de apoyo del sobreviviente como su familia, amigos. Las instituciones formales de salud mental, bienestar social y justicia son el último recurso.

Para restablecer la seguridad del paciente es indispensable enfocarse primero en su control del cuerpo y en sus intentos graduales para manejar su medio ambiente. El control corporal incluye prestarle atención a las necesidades de salud básicas, la regulación de las funciones del cuerpo como dormir, comer y ejercitarse, el manejo de los síntomas post traumáticos y el control de las conductas autodestructivas. Los asuntos ambientales toman en cuenta el establecimiento de una situación de vida financiera segura, la movilidad y un plan de auto protección que acompasa el rango total de la vida diaria del paciente. Debido a que nadie puede establecer un ambiente seguro por sí mismo, la tarea de desarrollar un plan de seguridad adecuado incluye siempre el apoyo social.

$2^{\circ}$ En casos de un trauma único reciente, el control del cuerpo comienza con la atención médica a cualquier herida que el sobreviviente haya sufrido. El principio del respeto a la autonomía del paciente es de gran importancia desde un principio, aún en el examen médico rutinario y tratamiento de las heridas.

Una vez que el cuidado médico ha sido otorgado, el control del cuerpo se dirige a la restauración de los ritmos biológicos del comer y dormir, como a reducir la sobre excitación y los síntomas intrusivos. Si el sobreviviente es altamente sintomático, se debe considerar medicación.

Lapersona severamente traumatizada necesita un refugio seguro. Encontrarlo y asegurarlo es la tarea 
inmediata a la intervención de la crisis. En los primeros días o semanas que siguen al trauma agudo, el sobreviviente puede querer aislarse en su casa o puede no ser capaz de ir a ella para nada. Si el perpetrador del trauma es un miembro de la familia, la casa es el lugar más inseguro para escoger. La intervención a la crisis puede requerir un cambio literal de refugio. Una vez que la persona traumatizada lo ha establecido, puede gradualmente progresar hacia esferas más amplias de compromiso con el mundo. Puede tomar semanas el sentirse seguro para reasumir actividades ordinarias como manejar, comprar, visitar amigos o ir a trabajar. Cada nuevo ambiente debe ser monitoreado y asegurado con relación a su potencial de seguridad o peligro.

Las relaciones del sobreviviente con otra gente tienden a oscilar entre dos extremos mientras intenta establecer un sentido de seguridad. Puede querer estar siempre rodeado de gente o puede aislarse completamente. Los miembros de la familia y amigos cercanos pueden ser de inmensa ayuda, pero también pueden interferir en la recuperación o ser ellos mismos fuente de peligros. Una evaluación inicial de la persona traumatizada incluye una revisión cuidadosa de las relaciones importantes en su vida y del papel que juegan como fuente potencial de protección, apoyo emocional, ayuda práctica o como fuente posible de peligro. Si las relaciones familiares o amicales de apoyo no ofrecen garantía, es mejor evitarlas.

$3^{\circ}$ En casos de trauma agudo reciente, la intervención en la crisis incluye usualmente reuniones con los miembros que más apoyan en la familia. La decisión sobre realizar o no realizar dichas reuniones, a quién invitar y qué clase de información compartir, queda en último caso a criterio del sobreviviente. Debe quedar claro que el propósito de las reuniones es alentar la recuperación del sobreviviente, no tratar a la familia. Un poco de educación preventiva sobre desórdenes post traumáticos, sin embargo, podría ser de ayuda para todos los involucrados. Los miembros de la familia no solo ganan conocimientos sobre la manera de apoyar al sobreviviente, sino que también aprenden cómo enfrentar sus propios traumas. Es común que durante estas reuniones salgan o sean traídas a luz las tensiones subyacentes en las relaciones familiares.

Establecer un ambiente seguro requiere no sólo de la movilización de la gente que se preocupa del paciente, sino también del desarrollo de un plan para su protección futura.

$4^{\circ}$ Si el apoyo social adecuado está disponible, los sobrevivientes de un trauma agudo único recuperan su rudimentario sentido de seguridad en unas semanas y luego de tres meses, se puedeesperar la estabilización de los síntomas, pero si encuentra un ambiente hostil o sin protección o tiene que enfrentarse a problemas fuera de su control como procedimientos legales, entre otras cosas, ese proceso puede estropearse o frustrarse.

Es razonable esperar que la tarea terapéutica de la primera etapa de recuperación pueda llevarse dentro de un esquema general de intervención de crisis o psicoterapia de corto plazo.

5을 Con sobrevivientes de traumas prolongados y repetidos, la etapa inicial de recuperación puede ser extensa y difícil debido al grado en que la persona traumatizada se ha vuelto un peligro para ella misma. Esos peligros pueden incluir auto daño activo, fallas pasivas de autoprotección y dependencia patológica con el abusador. Para hacerse cargo de su propio cuidado, el sobreviviente debe reconstruir cuidadosamente las funciones del ego que están más severamente dañadas, recuperar la habilidad de tomar la iniciativa, llevar a cabo planes y ejercitar su juicio independiente. La mera intervención en la crisis o la terapia breve son insuficientes para establecer la seguridad en ese paciente, se requiere por lo general de un tratamiento prolongado de psicoterapia.

6ํㅡ Con los sobrevivientes de abuso infantil crónico, establecer la seguridad puede resultar una tarea extremadamente larga y compleja. El paciente interrumpe casi siemprey de manera severa las medidas de auto protección. Esta conducta puede tomar numerosas formas, incluyendo intentos crónicos de suicidios, auto mutilación, desórdenes alimenticios, abuso de sustancias, toma impulsiva de riesgos e involucramiento repetitivo en relaciones explotadoras o peligrosas. Muchas conductas auto destructivas pueden interpretarse como reactuaciones simbólicas o literales del abuso inicial y sirven para regular el intolerable estado de los sentimientos ante la ausencia de estrategias auto tranquilizantes más adaptables. Es imprescindible que el paciente reconstruya cuidadosamente en su vida posterior las capacidades 
para cuidarse y tranquilizarse a sí mismo, que no pudo desarrollar en ambientes de abuso infantil.

Esta meta puede ser inicialmente un punto de controversia entre el paciente y el terapeuta. El paciente que está invirtiendo en una fantasía de rescate, puede resentirse por tener que hacer este trabajo, cuando supone o quiere que sea el terapeuta quien lo lleve a cabo. Un paciente cargado de auto repugnancia, por ejemplo, puede sentir que no merece un buen tratamiento. En ambas instancias, conviene al terapeuta trabajar con el sentimiento más adecuado para que el paciente afirme su seguridad.

Como sucede en los casos de traumaúnico agudo, la seguridad del paciente comienza con la recuperación del control de su cuerpo y continua con la autoprotección y la organización de un ambiente seguro.

En el proceso de restablecer la seguridad y el cuidado propio básicos, el paciente es llamado a planear, a iniciar la acción y a usar su mejor juicio para conseguir esos objetivos. Mientras empieza a ejercitar esas capacidades, minadas sistemáticamente por el abuso repetido, mejoran su sentido de competencia, auto estima y libertad. Paralelamente, el paciente comienza a brindarle algo de confianza al terapeuta, apoyándose en su compromiso de conseguirle su seguridad.

Un ambiente seguro para el paciente no sólo depende de su capacidad psicológica para protegerse, sino también de sus posibilidades sociales reales, es decir, lo que le permite o le obstaculiza su medio ambiente concreto. Aún cuando el paciente haya recuperado un sentido de auto cuidado confiable, puede carecer de un ambiente suficientemente seguro para avanzar en su recuperación, por lo que se hace necesario que el terapeuta explore a profundidad los eventos traumáticos.

Sin libertad, no puede haber seguridad ni recuperación, pero la libertad hay que conseguirla y usualmente a un gran costo. Para lograr esa libertad, los sobrevivientes tienen que abandonar casi todo; casa, país, etc. Las mujeres golpeadas pueden perder su hogar, sus amigos y su modo de vida. Los sobrevivientes de abuso infantil pueden perder a su familia. Los refugiados políticos pueden perder sus hogaresy sus patrias. Raramente se reconoce la enorme dimensión de esos sacrificios.

Los pacientes a veces insisten en sumergirse en descripciones gráficas y detalladas de sus experiencias traumáticas, en la creencia de que simplemente sacando la historia a la luz resolverán sus problemas. En la raíz de esta creencia, está la fantasía de una cura catártica violenta que los deshará del trauma de una vez por todas. El paciente puede imaginar una clase de orgía sadomasoquista en la cual gritará, llorará, vomitará, sangrará, morirá y renacerá limpio del trauma. El rol del terapeuta en esta reactuación llega a acercarse incómodamente al del perpetrador, ya que se le invita a rescatar al paciente a través del dolor. El deseo del paciente por esta clase de cura rápida y mágica se apoya en las imágenes de los primeros tratamientos catárticos de síndromes traumáticos como los que ahora llenan la cultura popular, así como la antigua metáfora religiosa del exorcismo.

Para contradecir la fantasía de una cura rápida y catártica, el terapeuta puede comparar el proceso de recuperación a una carrera de maratón. Los sobrevivientes inmediatamente aceptan la complejidad de estas imágenes. Reconocen que la recuperación, tal como la maratón, es una prueba de resistencia, que requiere de una larga preparación y una práctica repetitiva. La metáfora de la maratón captura la conducta enfocada al condicionamiento del cuerpo, así como las dimensiones psicológicas de la determinación y el coraje. Aunque la imagen puede carecer de una dimensión social fuerte, captura el sentimiento inicial del aislamiento del sobreviviente y ofrece una imagen del rol del terapeuta como el de un entrenador. La técnica experta, el juicio y el apoyo moral del terapeuta son vitales para la empresa, pero, al final, es el sobreviviente quien determina su recuperación a través de sus acciones.

No hay un evento único, dramático. La transición es gradual, ocurre a través de arranques y primeros pasos. Poco a poco, la persona traumatizada vuelve a ganar algún sentido rudimentario de seguridad o por lo menos predecible en su modo de tratar su vida. La víctima encuentra, una vez más, que puede contar consigo misma y con otros. Aunque puede ser más cautelosa y menos confiada de lo que era antes del trauma y por lo mismo, trate aún de evitar la intimidad, puede no sentirse completamente vulnerable o aislada. 
Tiene alguna confianza en su habilidad para protegerse; sabe cómo controlar sus síntomas más perturbadores y sabe en quién se puede apoyar. El sobreviviente de trauma crónico empieza a creer que no sólo puede cuidarse muy bien él mismo, sino que no merece menos que eso. En sus relaciones con los otros, ha aprendido a ser confiable y auto protector. En su relación con el terapeuta, ha concertado una alianza razonablemente segura que preserva a la autonomía de cada uno y la conexión entre los dos.

Lapsicoterapia ambulatoria puede ser inadecuada o totalmente inapropiada en un paciente cuyo auto cuidado o auto protección están en una situación muy deficitaria. El paciente puede necesitar inicialmente un tratamiento diario, cerca de la casa o ser referido a un programa de tratamiento de alcohol o drogas. Puede requerir que se lo hospitalice para desintoxicarlo, controlar sus desórdenes alimenticios o prevenir un suicidio. Las intervenciones sociales necesarias incluyen el reporte de los niños en riesgo a los servicios de protección, la obtención de órdenes de protección civil o conseguirle al paciente el traslado a un refugio.

\section{Tercera etapa: Recuerdo y lamento}

El trabajo de reconstrucción realizado por el terapeuta transforma la memoria traumática de manera que pueda ser integrada en la historia de vida del sobreviviente. El recuento inicial del evento por parte del paciente puede ser repetitivo, estereotipado y sin emotividad. Un observador describe este modo de presentar la historia del trauma en su estado no transformado, como un acto «pre narrativo», en el que no se desarrolla o progresa en el tiempo, no se revelan los sentimientos de quien cuenta la historia, ni se llega a interpretar sus eventos. Otro terapeuta lo describe como una serie de instantáneas fijas o una película muda; quedando en manos de la terapia proporcionarle a esa historia la música y las palabras.

La reconstrucción del trauma requiere del paciente y del terapeuta una gran demanda de coraje y que ambos sean claros en su propósito y seguros en su alianza.

Mientras el sobreviviente emplaza sus memorias, es indispensable balancear la necesidad de preservar la seguridad con la de enfrentar el pasado. El paciente y el terapeuta juntos deben aprender a negociar un pasaje seguro entre los peligros de la constricción y la intrusión. Evitar las memorias traumáticas lleva al estancamiento del proceso de recuperación, mientras que la aproximación precipitada a las mismas pone al paciente en situación de revivir el trauma de modo dañino y sin sentido.

Las decisiones que tienen que ver con el paso y el tiempo necesitan una meticulosa atención y una revisión frecuente de estos asuntos por el paciente y el terapeuta, las diferencias de opinión deben ser aireadas libremente y resueltas antes de que proceda el trabajo de reconstrucción.

Los síntomas intrusivos del paciente deben monitorearse cuidadosamente de manera que el trabajo descubierto quede dentro del límite de lo que es soportable. Si los síntomas empeoran dramáticamente durante una exploración activa del trauma, debe reconocerse una señal para reconsiderar el curso de la terapia o para retardarla. El paciente también debe considerar que durante esta etapa, no podrá funcionar al más alto nivel de su capacidad o inclusive, a su nivel usual. Reconstruir el trauma es un trabajo ambicioso, requiere de un relajamiento de las demandas de la vida ordinaria, una tolerancia al hecho de estar enfermo.

Este proceso puede funcionar dentro del esquema de trabajo social ordinario y diario del paciente. Ocasionalmente, las demandas del trabajo terapéutico pueden requerir una hospitalización planificada u otro tipo de protección. El trabajo descubierto activo no debe emprenderse en momentos en que la crisis inmediata de la vida captura la atención del paciente 0 cuando se enfrenta a metas más prioritarias.

Reconstruir la historia del trauma empieza con una revisión de la vida anterior al mismo y las circunstancias que condujeron al incidente. El paciente debe ser alentado a expresarse sobre sus relaciones importantes, sus ideales y sueños, sus luchas y conflictos anteriores al evento traumático.

Lasiguiente etapa consiste en reconstruir el evento traumático como una descripción distante y no comprometida del hecho. Con los elementos fragmentarios y emocionalmente congelados de la imagen del incidente, paciente y terapeuta reorganizan la historia lentamente, de modo detallado, verbal y orientado en el tiempo y el contexto histórico. La narración incluye no solo el evento mismo, sino 
también las reacciones del paciente y las de la gente importante en su vida. Conforme la narración se cierra en los momentos más insoportables, el paciente va encontrando cada vez más difícil usar las palabras.

Una narración que no incluye las imágenes traumáticas y sensaciones corporales es estéril e incompleta. Pueden faltarle al paciente las palabras, puede serle cada vez más difícil utilizarlas, sin embargo, la meta final de esta etapa de la terapia es lograr que ponga en palabras toda la historia del hecho traumático, incluyendo las imágenes del mismo. Los primeros intentos del paciente para desarrollar el lenguaje narrativo pueden estar parcialmente disociados, puede escribir su historia en un estado alterado de conciencia y luego desconocerlo puede tirar, esconder u olvidar lo que ha escrito o puede dárselo al terapeuta, con el pedido de que sea leído fuera de la sesión terapéutica.

El terapeuta debe ser consciente de desarrollar un "Canal de Respuesta" de comunicación apartado, recordándole al paciente que la meta mutua es traer la historia al consultorio donde pueda ser contada y escuchada. Las comunicaciones escritas deben ser leídas en conjunto.

El recitado inicial de los hechos sin el acompañamiento de emociones es un ejercicio estéril, sin efecto terapéutico, útil únicamente para dar comienzo al tratamiento. Tal como Breuer y Freud notaron un siglo atrás, «el recuerdo sin afecto casi invariablemente no produce ningún resultado». En cada punto de la narración, entonces, el paciente debe reconstruir no solo lo que pasó, sino también lo que sintió. La descripción de los estados emocionales debe ser tan cuidadosamente detallada como la descripción de los hechos. Mientras el paciente explora sus sentimientos, puede agitarse o retirarse. No está describiendo simplemente lo que vivió en el pasado, sino que está reviviendo aquellos sentimientos en el presente. El terapeuta debe ayudar al paciente a moverse en el tiempo, desde su anclaje en el presente hasta su inmersión en el pasado, de manera que pueda reexperimentar simultáneamente los sentimientos en toda su intensidad, mientras mantiene el sentido de conexión segura que fuera destruida en el momento del hecho traumático.
El terapeuta reta a una persona ordinaria a volverse un teólogo, un filósofo y un jurista. El sobreviviente es llamado a articular los valores y creencias que alguna vez tuvo y que el trauma destruyó. Está mudo ante el vacío de la maldad, sufriendo la insuficiencia de cualquier sistema conocido de explicación. Los sobrevivientes de atrocidades en cada edad y en cada cultura, llegan a un punto en su testimonio en el que las preguntas se reducen sólo a una, la esencial, la que los deja más aturdidos que sorprendidos: ¿Por qué? La respuesta está más allá de la comprensión humana.

Después de esta pregunta impenetrable, aparece otra, igualmente incomprensible: ¿Por qué yo? ¿Por qué a mí?. La calidad arbitraria y fortuita de su destino desafía la fe humana básica en un orden mundial justo e inclusive predecible. Para poder desarrollar una comprensión completa de la historia del trauma, el sobreviviente debe examinar las preguntas morales de culpabilidad y responsabilidad y reconstruir un sistema de creencias que le otorgue sentido a su inmerecido sufrimiento. Llega a un punto en que no puede reconstruir ese sentido por el solo ejercicio del pensamiento, si no considera la necesidad de tomar acción. El sobreviviente debe decidir qué es lo que se debe hacer.

Estas preguntas suelen enfrentarlo con gente importante en su vida, rompe con su sentido de pertenencia a un sistema compartido de creencias, ha perdido la fe, la aceptación de unos valores consagrados, el paciente se encuentra delante de una doble tarea- no sólo debe reconstruir sus propias "Suposiciones Rotas" sobre el significado, orden y justicia en el mundo, sino que también debe encontrar una manera de resolver sus diferencias con aquellos cuyas creencias no puede compartir más. No sólo debe restaurar su propio sentido de los valores, sino que debe también prepararse para sostenerlo frente a la crítica de los demás.

La instancia moral del terapeuta es por lo tanto de enorme importancia. No es suficiente que el terapeuta sea «neutral» o «que no emita juicio». Su rol no es proveer respuestas prefabricadas, lo que sería imposible en cada caso, sino más bien afirmar una posición de solidaridad moral con el sobreviviente.

A través de la exploración de la historia traumática, el terapeuta está llamado a proveer un contexto que es 
al mismo tiempo cognitivo, emotivo y moral. Normaliza las respuestas del paciente, facilita el uso del lenguaje y comparte la carga emocional del trauma, contribuye también a construir una nueva interpretación de la experiencia que afirme la dignidad y el valor del sobreviviente.

Mientras el terapeuta escucha, debe recordar constantementeque no puede hacer ninguna presunción sobre los hechos o el significado del trauma para el paciente. Si falla al hacer preguntas detalladas, arriesga imponer sus propios sentimientos y su propia interpretación de la historia. Lo que parece un detalle menor para el terapeuta, puede ser el aspecto más importante de la historia para el paciente. Contrariamente, un aspecto de la historia que el terapeuta encuentra intolerable, puede tener poco peso para el paciente. Aclarar estos puntos de vista discrepantes mejorará el entendimiento mutuo de la historia traumática.

Tanto el paciente como el terapeuta deben tolerar cierto grado de incertidumbre y vivir en la ambigüedad mientras exploran el curso que lleva hacia una paz tolerable, aún luego de confirmar los hechos básicos de la historia, porque a lo largo de su reconstrucción, esta puede cambiar a medida que se recuperan las piezas que faltan, lo cual es particularmente cierto cuando el paciente ha experimentado brechas significativas en su memoria.

Algunas veces, los terapeutas son también presas de la tentación de la certidumbre. Unas convicciones celosas pueden reemplazar muy fácilmente a una actitud abierta e intrigante. En el pasado, esta tentación solía llevar a los terapeutas a descontar o minimizar las experiencias traumáticas de sus pacientes. El terapeuta tiene que recordar que él no es un localizador de hechos y que la reconstrucción de la historia traumática no es una investigación criminal. Su rol es el de testigo compasivo de mente abierta, no un detective.

Debido a que la verdad es tan difícil de enfrentar, los sobrevivientes tienden a vacilar en la reconstrucción de sus historias. La negación de la realidad los hace temer que se están asomando a la locura, pero su aceptación total parece estar más allá de lo que cualquier ser humano puede soportar.
En el proceso de reconstrucción, la historia traumática pasa por una transformación, pero sólo en cuanto se vuelve más presente y real. La premisa fundamental del trabajo psicoterapéutico es la creencia en el poder restaurador de la verdad. Es entonces cuando la historia traumática comienza a volverse un testimonio. Este consta tanto de una dimensión privada, que es espiritual y confesional, como de una de valor público, política y judicial. El uso de la palabra testimonio une ambos significados, otorgándole una dimensión nueva y mayor a la experiencia individual del paciente.

Existen dos técnicas altamente evolucionadas para enfrentar la narración de las historias: La "Exposición Directa" o "Inundación" en el tratamiento de veteranos de combate y el "testimonio", formalizado para el tratamiento de sobrevivientes de torturas.

La técnica de inundación es parte de un programa intensivo, es una terapia de conducta designada para vencer el terror del evento traumático exponiendo al paciente a volver a vivir controladamente la experiencia. En la preparación de las sesiones de inundación, se le enseña al paciente cómo manejar la ansiedad usando técnicas de relajación y visualizando imágenes tranquilizadoras.

Entonces, el paciente y el terapeuta preparan cuidadosamente un "guión" escrito, describiendo el evento traumático en detalle. Este guión incluye cuatro elementos: de contexto, de hecho, de emoción y de significado. Si hubiera algunos eventos traumáticos, se desarrolla un guión separado para cada uno. Cuando los guiones se completan, el paciente escoge la secuencia para su presentación en las mismas sesiones de inundación, progresando desde la más fácil hasta la más difícil. En una sesión de inundación, el paciente narra su guión en voz alta y en tiempo presente, mientras el terapeuta lo reta a expresar sus sentimientos lo más completamente posible. Este tratamiento se repite semanalmente en un promedio de doce a catorce sesiones.

La "Acción de Contar la Historia" dentro de la seguridad que brinda una relación protegida puede realmente modificar el proceso anormal de la memoria traumática y generar el alivio de muchos de los síntomas más grandes del desorden de estrés post traumático. La fisioneurosis inducida por el terror es capaz de ser revertida mediante el uso de la palabra. 
Las técnicas efectivas para aproximarse a estos eventos traumáticos pueden no ser adecuadas para los casos de abuso crónico, particularmente entre sobrevivientes que sufren de vacíos nemotécnicos. El tiempo requerido para reconstruir historias completas de esta índole toma mucho más que 12, 14 o 20 sesiones.

\section{Cuarta etapa: Reconexión}

Habiendo resuelto su pasado traumático, el sobreviviente enfrenta la tarea de crearse un futuro. Ha llorado a su yo anterior, destruido por el trauma y ahora debe desarrollar un nuevo yo; sus relaciones han sido probadas y cambiadas para siempre por el trauma y es el momento de desarrollar nuevas relaciones. Las creencias antiguas que dieron significado a su vida han sido desafiadas ahora ella debe encontrar una nueva fe que la sostenga.

Los sobrevivientes recuperados se sienten como refugiados entrando a un nuevo país. Para los exiliados políticos, esto puede resultar una verdad literal; pero para muchos otros, como las mujeres golpeadas o los sobrevivientes de abuso infantil, la experiencia psicológica del reingreso sólo puede ser comparada a la inmigración, deben construir una nueva vida dentro de una cultura radicalmente diferente a la que dejaron detrás. Emergiendo de un ambiente de total control, deben sentir simultáneamente la maravilla y la incertidumbre de la libertad, de perder un mundo y volver a ganar otro.

El sobreviviente vuelve a consagrar su energía al cuidado de su cuerpo, su ambiente inmediato, sus necesidades materiales y sus relaciones con los otros, pero mientras que en la primera etapa, la meta era simplemente asegurar una posición defensiva de seguridad básica, en esta, el sobreviviente está listo para comprometerse más activamente con el mundo, utilizar su nueva seguridad para aventurarse hacia delante, establecer una agenda, recuperar algunas de las aspiraciones del tiempo anterior al trauma o quizás, descubrir sus propias ambiciones por primera vez.

La desesperanza y el aislamiento son las experiencias esenciales del trauma psicológico, como el empoderamiento y la reconexión la esencia de la recuperación. La persona traumatizada reconoce que ha sido una víctima y comprende los efectos de su victimización. Está lista para incorporar las lecciones de la experiencia traumática en su vida, está lista para dar pasos concretos, incrementar su sentido de poder y control, protegerse contra daños futuros y profundizar sus alianzas con aquellos en quienes ha aprendido a confiar.

Esta reconexión se desarrolla a través de las siguientes fases:

\section{a) Aprendiendo a pelear}

Tomar el poder en situaciones de la vida real involucra una decisión consciente de enfrentar un peligro. En esta etapa de recuperación, los sobrevivientes entienden que sus síntomas post traumáticos representan una exageración patológica de las respuestas normales al peligro. Usualmente, están bastante conscientes de su continua vulnerabilidad a las amenazas y recordatorios del trauma. Más que aceptar pasivamente estas experiencias revividas, los sobrevivientes pueden escoger enfrentar activamente sus temores. En un nivel, la alternativa de exponerse al peligro puede ser comprendida como otra reactuación del trauma, pero a diferencia de la reactuación, esta alternativa es un intento consciente, planificado y metódico de manejar la experiencia traumática y por consiguiente, es más factible que se logre.

Al escoger "Probar el Miedo", los sobrevivientes se ponen a sí mismos en posición de reconstruir las respuestas fisiológicas normales al peligro y el «sistema de acción» lesionado y fragmentado por el trauma. Como resultado, se enfrentan al mundo con más confianza.

Hay otros desafíos controlados y disciplinados del temor, que pueden ser igualmente importantes para los sobrevivientes en esta etapa de recuperación.

Hombres y mujeres cuestionan sus roles tradicionales, ellas, su aceptación de la subordinación, ellos, su complicidad tradicional en una jerarquía de dominio, dos presunciones y conductas tan engranadas, que se llevan a cabo de manera inconsciente.

La exploración franca, arriesgada y amplia de las debilidades y errores de la persona traumatizada solo puede asumirse dentro de un ambiente que la proteja contra la vergüenza, el juicio ajeno y hasta la repulsa de los demás. De otra manera, se convierte en otro ejercicio de culpabilidad para la víctima. 
De la misma manera que los pacientes deben enfrentar sus propios temores y conflictos internos, deben también sobreponerse a las presiones sociales del medio ambiente, de otra manera, continuarán repitiendo en su vida diaria las conductas simbólicas de su trauma.

Mientras que en la primera etapa de recuperación, los sobrevivientes lidian con la adversidad social al aislarse en un ambiente protegido, en la segunda, pueden sentir la tentación de confrontar a los demás y al medio en el que viven. Es en este punto, que los sobrevivientes están listos para revelar sus secretos, desafiar la indiferencia o censura de quienes están a su lado y acusar a aquellos que los violentaron.

\section{b) Reconciliándose con el Yo}

Una simple frase como: "Sé que me tengo a mí mismo", puede servirle de emblema al sobreviviente para enrumbar el proceso de reconciliarse con su yo. Ya no se siente capturado por su pasado traumático; está en posesión de sí mismo, goza de algún conocimiento del tipo de persona que era y del daño que le causó el evento traumático, su tarea ahora es convertirse en la persona que anhela ser. Alo largo de ese proceso, integra los aspectos de sí mismo anteriores al trauma que más valora, la experiencia del trauma como tal y el período de recuperación que está viviendo, creando un nuevo yo tanto ideal como real.

La recreación de un yo ideal involucra el ejercicio activo de la imaginación y la fantasía, capacidades que gozan de una nueva libertad. En su etapa traumatizada, la fantasía de vida del sobreviviente estaba dominada por las repeticiones del trauma y su imaginación acorralada por la desesperanza y la inutilidad de su ser. Ahora, el sobreviviente ha ganado la capacidad de revivir viejas esperanzas. Es posible que al inicio se resista a soñar, temiendo el dolor de la decepción, pero al abandonar la asfixiante sensación de ser una víctima, toma coraje y asume, pero así como debe osar confrontar sus temores, debe también atreverse a definir susdeseos.

El trabajo de terapia suele enfocarse en el desarrollo del deseo y la iniciativa. El ambiente terapéutico permite un espacio protegido en el cual, la fantasía puede moverse con libertad. También es un fundamento de prueba para el traslado de esa fantasía a una acción concreta. La auto disciplina aprendida en las primeras etapas de la recuperación puede fortalecer la imaginación y la capacidad lúdica del sobreviviente. Este es un período de aciertos y de errores, de aprender a tolerar las equivocaciones y de saborear los logros inesperados.

Ganar la posesión de uno mismo requiere repudiar aquellos aspectos del yo impuestos por el trauma. Mientras el sobreviviente se desprende de su identidad de víctima, puede también escoger renunciar a partes de él mismo que hasta ese momento consideraba casi inherentes a su ser. Una vez más este proceso reta las capacidades del sobreviviente para la fantasía y la disciplina.

Mientras el sobreviviente se reconecta consigo mismo, gana en serenidad y capacidad de enfrentar la vida con ecuanimidad. En ocasiones, esta pacificada existencia diaria puede parecer extraña, especialmente para sobrevivientes criados en ambientes traumáticos que experimentan la normalidad por primera vez. Así como anteriormente imaginaba que la vida ordinaria sería una rutina gris, ahora se aburre de su vida de víctima y está listo para encajar con la interesante vida ordinaria.

Cuando los sobrevivientes reconocen y «dejan ir» aquellos aspectos de su personalidad construidos en ambientes traumáticos, adquieren el sabio don de ser más indulgentes consigo mismos, reconocen que los daños sufridos no tienen por qué ser permanentes y los aceptan como una marca transitoria que ni los encadena ni los rebaja. Cuanto más activos estén los sobrevivientes para comprometerse a reconstruir sus vidas, más generosos y receptivos serán con los recuerdos de su yo traumatizado.

La compasión y el respeto por el yo victimado y traumatizado se abrazan con la celebración del yo sobreviviente, el orgullo de ser quien se es vive un salto renovado y la estima por sí mismo se eleva. La saludable admiración por el yo difiere del grandioso sentimiento de ser especiales que a veces se encuentra entre la gente victimada y que compensa al yo por la auto aversión y el sentimiento de valer poco o nada. Siempre quebradiza, esta fantasía de «diferencia» no admite imperfecciones, carga con un sentimiento de ser alguien separado de ese resto que son los otros. $A$ diferencia de la víctima que sigue siendo víctima y "diferente", el sobreviviente recuperado es totalmente 
consciente de su ordinariez, su debilidad y sus limitaciones, así como de su conexión con los demásy el hecho de no deberle nada a los otros en su calidad de ser. Esta conciencia establece un balance, aún si se regocija con los puntos fuertes de su personalidad.

\section{c) Reconectándose con otros}

El sobreviviente recuperado gana alguna capacidad para confiar apropiadamente en los otros, puede guardar la confianza cuando está garantizada, retenerla cuando no lo está y saber distinguir entre ambas situaciones. También es capaz de ganar en habilidad de sentir autonomía mientras permanece conectado con otras personas, mantener su propio punto de vista y sus propios límites, respetando los de los demás. Ha empezado a tomar más iniciativas en su vida y está en proceso de crear una nueva identidad, como también listo para arriesgarse a profundizar sus relaciones, buscar amistades mutuas que no estén basadas en el desempeño, la imagen o el mantenimiento de un falso yo, es capaz de establecer una mayor intimidad en el amor y con la familia.

Esta profundización de las conexiones también se nota en la relación con el terapeuta, la alianza terapéutica se siente menos intensa, pero más relajada y segura, hay espacio para más espontaneidad y humor, las crisis e interrupciones son poco frecuentes y las sesiones más continuas, el paciente goza de mayor capacidad para la auto observación y mayor tolerancia con el conflicto interno. Con el cambio en la apreciación de sí mismo, viene el cambio de apreciación por el terapeuta, el paciente lo idealiza menos, tiende a perdonar sus limitaciones, así como las suyas propias y el trabajo comienza a sentirse como una psicoterapia ordinaria.

El paciente que ha crecido en un ambiente abusivo, no ha podido vivir como es debido, su primera adolescencia, y carece de las habilidades sociales que se desarrollan normalmente durante esta etapa de la vida. La torpeza y la auto conciencia que hacen de la adolescencia normal un trayecto tan tumultuoso y doloroso, son magnificadas por los sobrevivientes adultos, quienes suelen sentirse exquisitamente avergonzados de su «torpeza» en habilidades que otros adultos dan por sentadas. No es raro que se valgan de estrategias sociales «atrasadas». Así como los adolescentes se ríen para protegerse de la confusión, los adultos sobrevivientes pueden encontrar en la risa un antídoto a su vergüenza o desarrollar nuevas e intensas lealtades mientras reconstruyen su vida, del mismo modo como los adolescentes se unen en amistades muy cercanas para arriesgarse a explorar un mundo mayor.

El retroceso del trauma levanta las barreras para ahondar la intimidad. En este punto, el sobreviviente puede estar listo para dedicarle su energía a una relación de pareja. Si no está involucrado en ninguna, puede empezar a considerar la posibilidad de estarlo sin sentirse amenazado o desesperado por tenerla. Si ha mantenido una relación durante el proceso de recuperación, se volverá mucho más consciente de las maneras en que su pareja vivió su preocupación por el trauma. En este punto, el paciente puede expresarle su gratitud más libremente y hacer las correcciones que creanecesarias.

La intimidad física presenta una barrera particular para los sobrevivientes de un trauma sexual. El proceso fisiológico de la excitación y del orgasmo pueden verse comprometidos por memorias traumáticas intrusivas, así como los sentimientos y las fantasías sexuales. Reclamar la propia capacidad para el placer sexual es un asunto complicado, trabajarlo con un compañero o compañera es más complicado aún. Las técnicas para tratar la disfunción sexual post traumática recomiendan por lo general el incremento del control del paciente sobre cada aspecto de su vida sexual. Incluir una pareja requiere un alto grado de cooperación, compromiso y auto disciplina de ambas partes.

Los hijos son otro campo en el que el avance en la curación del estrés post traumático decreta cambios perceptibles. Mientras el paciente termina de entender lo que ha significado el trauma en su propia vida, puede abrirse a nuevas formas de compromiso con sus hijos. Si se trata de un padre, puede llegar a reconocer el modo cómo su experiencia del trauma los afectó y dar los pasos necesarios para rectificar la situación. Si el paciente no tiene hijos, puede interesarse más por la gente menor, desear, por ejemplo, traer niños al mundo, si se trata de una mujer.

d) Encontrando una misión para el sobreviviente

Muchos sobrevivientes buscan la solución a su experiencia traumática dentro de los confines de su vida personal, pero una minoría significativa se siente llamada a comprometerse con un mundo más amplio 
como resultado del trauma, reconocen una dimensión política o religiosa en su mala fortuna y descubren que pueden transformar el significado de su tragedia personal poniéndola como base para una acción social. Si bien no hay manera de compensar la atrocidad, sí hay manera de trascenderla convirtiéndola en un don para con otros. El trauma es redimido solo cuando se vuelve la fuente de una misión para el sobreviviente.

La acción social ofrece al sobreviviente una fuente de poder que dibuja su propia iniciativa, energía e ingenio, pero que magnifica estas cualidades mucho más allá de sus propias capacidades. Esto le permite aliarse con otras personas sobre una base de cooperación y propósito compartido. La participación en esfuerzos sociales organizados y demandantes llama a las estrategias más maduras y adaptables del sobreviviente como la paciencia, la anticipación, el altruismo y el humor. Saca lo mejor de sí y como recompensa, vive lo que significa conectarse con lo mejor de otras personas. A través de esta experiencia de conexión recíproca, el sobreviviente puede trascender los límites de su tiempo y su espacio particulares e inclusive, lograr un sentimiento de participación en un orden de creación que trasciende la realidad ordinaria.

La acción social puede tomar muchas formas, desde compromisos concretos con individuos particulares hasta la búsqueda intelectual abstracta. Los sobrevivientes pueden enfocar sus energías ayudando a otros que han sido victimados de la misma manera, desplegando esfuerzos educativos, legales o políticos para prevenir que otros sean victimados en el futuro o intentando llevar a los ofensores a la justicia. Uno de los esfuerzos más comunes es el de elevar la conciencia pública, los sobrevivientes comprenden perfectamente que la respuesta humana natural al horror y al sufrimiento es la evasión, ellos mismos lo han hecho en el pasado, igualmente, entienden que aquellos que olvidan el pasado están condenados a repetirlo. Es por esta razón, que decir la verdad públicamente es el denominador común de toda acción social.

Aunque el dar es la esencia misional de los sobrevivientes, aquellos que lo practican reconocen que lo hacen por su propia curación. Al cuidar de otros, se sienten reconocidos, amados y cuidados ellos mismos.
Buscar justicia es otro camino misional. Los sobrevivientes logran entender las razones que transcienden su agravio personal contra el perpetrador, reconocen queel trauma no puede deshacerse y que su deseo de compensación ovenganzanunca seconcretará completamente. Tienen claro sin embargo, qué hacer, que el perpetrador pague por sus crímenes es importante no solo para su bienestar personal sino también para el bien de toda la sociedad, redescubren un principio abstracto de justicia social que conecta el destino de los otros con el propio.

Aceptando la impersonalidad de la ley, los sobrevivientes se sienten aliviados en algún grado de la carga personal de la batalla. Es la ley y no ellos la que debe prevalecer. La queja o la acusación públicas desafían el intento del perpetrador de aislar su crimen o de mantenerlo en silencio y se abren a nuevas alianzas. Cuando el testimonio de un crimen es compartido, se comparte también la responsabilidad de restaurar la justicia, más aún, los sobrevivientes llegan a entender su propia batalla legal como una contribución en una lucha más grande, en la cual sus acciones pueden beneficiar a otros así como a ellos mismos.

El sentido de participación en una acción social significativa permite a los sobrevivientes enfrascarse en una batalla legal con el perpetrador desde una posición de fuerza. Como en el caso de confrontaciones familiares privadas, los sobrevivientes obtienen poder de su habilidad de levantarse en público y hablar la verdad sin temor de las consecuencias. Saben que la verdad es lo que más teme el perpetrador. Los sobrevivientes también obtienen la satisfacción de ejercitar públicamente el poder al servicio de ellos y de los otros.

Los sobrevivientes que asumen una acción pública también necesitan determinar el hecho de que no todas las batallas se ganarán. Su lucha particular se engrandece al integrarse a la que se libra para imponer las reglas de la ley sobre la tiranía arbitraria del poderoso. Este sentido de participación es, algunas veces, todo lo que tienen para sostenerse, la alianza con otros que los apoyan y creen en su causa, puede consolarlos en el caso eventual de la derrota.

Los sobrevivientes que eligen comprometerse en una batalla pública no pueden darse el lujo de eludir 
las posibilidades de una derrota, deben estar seguros de entender que con el simple deseo de confrontar al perpetrador se sobreponen a una de las consecuencias más terribles del trauma, han hecho saber que no pueden ser dominados por el temor y que han sido capaces de exponer públicamente el crimen y la condición malévola del perpetrador. La recuperación del paciente se apoya en la ilusión de que el mal ha sido derrotado y no ha prevalecido por completo, como en la esperanza de que el amor y su poder restaurador existen y pueden ser parte de ese mundo que tanto los agredió.

\section{e) Resolviendo el trauma}

Resolver el trauma no lo elimina por completo, la recuperación nunca es total, el impacto de un evento traumático continúa reflejándose a través de toda la vida, los asuntos suficientemente resueltos en una etapa de la recuperación pueden despertar y volver cuando los sobrevivientes se enfrentan a nuevos retos. Un matrimonio, un divorcio, un nacimiento o una muerte en la familia, una enfermedad o el retiro, son ocasiones propicias para que resurjan las memorias traumáticas.

Los mejores indicios de la resolución de un trauma son los que los propios sobrevivientes muestran cuando han logrado restaurar sus capacidades de aceptar el placer de vivir y de comprometerse completamente en las relaciones con otras personas, de elogiar el mundo más que temerlo, de interesarse más en el presente y en el futuro que en el pasado.

El curso de una recuperación no sigue una progresión simple, sino que avanza y regresa, revisando asuntos que ya han sido trabajados muchas veces, para profundizar y expandir la integración de los sobrevivientes con el significado de su experiencia.

Aquellos que han completado sus fases de recuperación con pocas ilusiones no dejan sin embargo de expresar su gratitud, pueden guardar una percepción trágica de la vida, pero por esa misma razón, aprenden a valorar la risa, tienen un claro sentido de lo que es importante y lo que no lo es, se han enfrentado a la maldad y por ello saben aferrarse a lo bueno, han visto el rostro de la muerte y por lo mismo han aprendido a celebrar la vida.

\section{Quinta etapa: Comunidad}

Los eventos traumáticos destruyen las vinculaciones sostenibles entre el individuo y su comunidad. Aquellos que han sobrevivido han aprendido que su sentido del yo, de su valor, de su humanidad, depende de su conexión con los otros. La solidaridad de un grupo provee la mejor protección contra el terror y la desesperación y el antídoto más eficaz contra la experiencia traumática. El trauma aísla; el grupo recrea un sentido de pertenencia. El trauma avergüenza y estigmatiza; el grupo soporta el testimonio y afirma. El trauma degrada a la víctima; el grupo la exalta. El trauma deshumaniza a la víctima; el grupo le restaura su humanidad. Aquello que piensan que ha sido irreparablemente destruido, como la fe, la decencia o el coraje, se vuelve a despertar por un ejemplo de altruismo común.

La restauración de los vínculos sociales empieza conel descubrimiento de que no seestá solo. En ningún lugar la experiencia es más inmediata, poderosa o convincente que en un grupo. Irvin Yalom, una autoridad en psicoterapia de grupo, llama a ésta la experiencia de la «universalidad». El impacto terapéutico de la universalidad es especialmente profundo para gente que se ha sentido aislada por secretos vergonzosos. Debido a que la gente traumatizada se siente tan alienada por su experiencia, los grupos de sobrevivientes tienen un lugar especial en el proceso de su recuperación. Dichos grupos proporcionan un grado de apoyo y comprensión que simplemente no está disponible en el ambiente social ordinario del sobreviviente.

Los grupos han probado ser invalorables para los sobrevivientes de situaciones extremas, incluyendo el combate, la violación, la persecución política, el maltrato físico y el abuso infantil. Los participantes lo describen repetidamente, consiguen su alivio con simplemente estar en presencia de otros que han pasado por pruebas similares.

Una sobreviviente de incesto expresa con sus propias palabras cómo volvió a ganar el sentimiento de conexión con otras personas al participar en un grupo que compartía su situación:

He roto el aislamiento en el que había estado toda mi vida. Tengo un grupo de seis mujeres con quienes no tengo secretos. Por primera vez en mi vida realmente creo pertenecer a algo. Me siento aceptada por lo que soy, no por mi fachada. 
Cuando los grupos desarrollan cohesión e intimidad, entra en juego un complejo proceso de reflejos. Cuanto más se abren los participantes hacia los demás, más permeables se vuelven a los dones que cado uno tiene para ofrecerles. La tolerancia, la compasión y el amor rebotan de unos a otros. Yalom describe este proceso como una «Espiral de Adaptación», la aceptación del grupo incrementa la autoestima de cada miembro y cada miembro se vuelve a su vez más tolerante hacia los otros.

Los grupos empoderan y proveen de relaciones provechosas. Los miembros se aproximan unos a otros como compañeros e iguales. Aunque cada uno esté sufriendo y necesite ayuda, cada uno tiene también algo con qué contribuir. El grupo requiere y cuida los puntos fuertes de cada uno de sus miembros. Como resultado, el grupo como un todo tiene la capacidad de soportare integrar la experiencia traumática, que es más grande que la de cualquier miembro individual y a su vez, cada miembro puede beber de los recursos compartidos para fomentar su propia integración.

Si bien en principio, los grupos de sobrevivientes son una buena idea, organizarlos no es una tarea sencilla. Pueden comenzarbrindando mucha esperanza y disolverse de manera áspera, provocando dolor y decepción en todos los involucrados. El potencial destructivo de los grupos es igual a su promesa terapéutica. El rol del líder del grupo conlleva un riesgo de ejercicio irresponsable de autoridad. Los conflictos que estallan entre los miembros pueden fácilmente recrear la dinámica de un evento traumático, con perpetradores, cómplices, testigos, víctimas y rescatadores. Dichos conflictos pueden ser tan hirientes para los participantes, que pueden matar al grupo. Un grupo exitoso debe tener una comprensión clara y enfocada de su tarea terapéutica y una estructura que proteja a todos los participantes de los peligros de la reactuación traumática. Aunque los grupos pueden variar ampliamente en composición y estructura, estas son condiciones básicas que no admiten excepciones.

Los grupos vienen en una variedad de tamaños y formas, y ninguno puede serlo todo para todas las personas. Hay diferentes tipos de grupo para las diferentes etapas de la recuperación. La tarea terapéutica primaria del individuo y del grupo debe ser congruente. Un grupo que puede encajar bien con una persona en una etapa de su recuperación, puede ser inefectivo o incluso dañino para la misma persona en otra etapa.

El grupo ayuda a enriquecer la historia de cada individuo, relevándolo de su aislamiento con el perpetrador y readmitiéndolo en la totalidad del mundo de donde fue retirado.

Un grupo enfocado en el trauma debe ser altamente estructurado y orientado hacia el descubrimiento del trabajo. El grupo requiere de líderes activos, bien preparados y miembros altamente comprometidos con una clara concepción de su tarea.

El enfoque en la meta personal provee un contexto integrador y empoderador para el trabajo de descubrimiento. A cada participante se le pide que defina una meta concreta y significativa relacionada al trauma y que la realice dentro del tiempo límite del grupo. Se le alienta a buscar la ayuda del grupo tanto para delinear la meta como para tomar las acciones necesarias para lograrla. Las metas escogidas más frecuentemente incluyen la recuperación de nuevas memorias o contarle parte de la historia a otra persona. Compartir la historia sirve a un propósito más allá de la simple ventilación o catarsis, es un medio para el dominio activo. El apoyo del grupo permite al individuo enfrentar riesgos emocionales que sobrepasan los que cree sus límites. Los ejemplos de coraje y logros individuales inspiran al grupo con optimismo y esperanza, aún si el grupo está inmerso en el horror y lapena.

El trabajo del grupo se enfoca en la experiencia compartida del trauma en el pasado, no en dificultades interpersonales en el presente. Los conflictos y las diferencias entre los miembros no son particularmente pertinentes para el grupo, puesto que lo desvían de su tarea. Los líderes deben intervenir activamente para promover que todos compartan sus experiencias y minimizar cualquier conflicto. En un grupo enfocado en el trauma, por ejemplo, los líderes asumen la responsabilidad de asegurar que cada miembro tenga la oportunidad de ser escuchado, sin permitir que nadie interrumpa o se pelee.

Un grupo enfocado en el trauma requiere de un liderazgo activo y comprometido. Los líderes son responsables de definir la tarea del grupo en un clima de seguridad para todos. Es un rol emocionalmente 
demandante, porque el líder debe establecer el ejemplo soportando los testimonios y demostrarle a los miembros que puede escuchar sus historias sin abrumarse.

Los grupos enfocados en el trauma tienen límites rígidos, sus miembros se unen y se apoyan rápidamente unos a otros. La partida o incluso la breve ausencia de un miembro puede tener un efecto muy desorganizador. En los grupos de tiempo limitado, los miembros deben planear su asistencia a cada reunión y ningún miembro nuevo debe ser admitido una vez que se haya comenzado a trabajar.

Un sobreviviente está listo para un grupo enfocado en el trauma cuando su seguridad y su auto ayuda han sido restablecidas con certeza, sus síntomas están bajo un control razonable, su apoyo social es confiable y las circunstancias de su vida permiten un compromiso en un ambiente demandante. Más allá de esto, sin embargo, debe desear comprometerse con la vida y enfocarla a través del grupo y sentirse razonablemente seguro de su deseo de alcanzar a otros sobre su miedo y temor al grupo.

Las recompensas a la participación en el grupo son proporcionales a sus demandas. Los reportes iniciales de cada miembro sobre el agravio que significan los síntomas de su aflicción lo cohesionan rápidamente y lo llenan de una euforia muy especial, aquella que se siente cuando uno se integra a un grupo de personas que han sufrido lo mismo y se atreven a comunicarlo, una euforia que se vincula al sentimiento de ser reconocido y comprendido por primera vez. Ese vínculo fuerte, hondo e inmediato es un rasgo predecible de grupos homogéneos de corto plazo.

La cohesión que se desarrolla en un grupo enfocado en el trauma, permite a los participantes embarcarse en las tareas del recuerdo y la lamentación. El grupo provee un estímulo poderoso para la recuperación de las memorias traumáticas. Como cada miembro del grupo reconoce su propia narración, los detalles de su historia casi invariablemente evocan nuevos recuerdos en cada uno de los que escuchan.

Debido a que un grupo enfocado en el trauma tiene vida limitada, mucho del trabajo integrador se logra al final. En los grupos de sobrevivientes de incesto, la clausura es altamente formal y todos sus integrantes ponen un gran esfuerzo y cuidado en los rituales de despedida. Acada participante se le pide que prepare por escrito una declaración de sus propios logros durante su participación en el grupo, así como un estimado del trabajo de recuperación que le queda por hacer, igualmente que prepare una declaración similar para cada uno de sus compañeros, con toda la empatía, imaginación y espíritu juguetón que les salga de los forros e información para los líderes del grupo. Cada uno se lleva no solo la experiencia de haber logrado una meta, sino también el recuerdo tangible del grupo. Los regalos imaginarios suelen reflejar el deseo de los miembros de compartir una parte de ellos mismos con aquellos que los acompañaron a enfrentar y salir del trauma. Un grupo enfocado en el trauma tiende a finalizar sus rituales de despedida orientando sus buenos deseos hacia lo que significa el valor de ser lo que se es y de quien se es.

El modelo de un grupo de tiempo limitado y con una meta establecida parece ser ampliamente aplicable, con ciertas variaciones, para sobrevivientes de muchas formas de trauma. Por contraste, el modelo de grupo de tiempo ilimitado débilmente estructurado se presenta menos apropiado para esa misma tarea, no genera la seguridad ni el enfoque necesarios para tomar el control terapéutico. Su eficiencia es muy limitada y sólo en algunos casos ha funcionado satisfactoriamente con sobrevivientes de trauma.

Cuando ungrupo está enfocado en el trauma puede convertirse en la alternativa más apropiada si se quiere atacar un problema específico relacionado con ese trauma que interfiere con el desarrollo de las relaciones más satisfactorias del presente.

La disfunción sexual post traumática es un problema que se presta fácilmente para una terapia de grupo enfocado y de tiempo limitado. El propósito es ayudar a cada participante a: "Ganar control sobre su sexualidad a través de la exposición gradual a situaciones sexuales inducidas con temor, conductase interacciones". Tanto el tratamiento individual como el grupal probaron ser altamente efectivos para controlar los síntomas relacionados con el trauma, así como las memorias retrospectivas de violación.

Problemas residuales como la hiperexcitación y el temor pueden ser atacados productivamente dentro de un trabajo grupal, tanto como una clase de auto 
defensa. Los instructores de auto defensa sofisticada reconocen la naturaleza intensamente emocional de su trabajo y comprenden su responsabilidad de crear un clima psicológico de seguridad, aunque ellos no se cataloguen como reclamos terapéuticos. El apoyo del grupo alienta a los sobrevivientes a intentar nuevos aprendizajes a pesar de sus temores, mientras el ejemplo desafiante de sus compañeros ofrece esperanza e inspiración.

Muchos sobrevivientes, especialmente aquellos que han pasado por un trauma prolongado y repetido, reconocen que el trauma ha limitado y distorsionado su capacidad de relacionarse con otra gente. El apoyo del grupo permite descubrir las conductas de mala adaptación social sin vergüenza excesiva y enfrentar el riesgo emocional de relacionarse de una nueva manera con otras personas.

Un grupo enfocado en relaciones interpersonales tiene una estructura completamente diferente al de un grupo enfocado en el trauma. El contraste en su estructura refleja las diferencias de su tarea terapéutica. El enfoque temporal del grupo interpersonal se estaciona en el presente, no en el pasado y sus miembros son alentados a preocuparse por sus interacciones en el aquí y el ahora.

Mientras los grupos enfocados en el trauma son usualmente de tiempo limitado, los interpersonales son típicos grupos de tiempo ilimitado, con una membresía estable y poco involucrada. Asimismo, los primeros son altamente estructurados, con un liderazgo activo y los segundos, de estructura relativa y con un estilo de liderazgo más permisivo.

La participación en un grupo interpersonal representa un gran reto para los sobrevivientes que se sintieron en algún momento totalmente fuera del entorno social y que pueden haber trabajado duro simplemente para llegar al punto en el que sienten que otros sobrevivientes pueden ser capaces de comprenderlos y ayudarlos a enfrentarse a la posibilidad de reunirse en un mundo más amplio y extender sus relaciones sociales.

Los sobrevivientes ingresan a un grupo psicoterapéutico interpersonal agobiados por el conocimiento de que el trauma sigue viviendo en sus relaciones diarias con otras personas. Una vez que abandonan el grupo, han aprendido que el trauma puede ser superado dentro de un compromiso activo con otros y que son capaces de comprometerse en relaciones mutuas. Aunque todavía sigue presente la huella indeleble de la experiencia pasada, pueden medir sus límites con amplitud y considerarla como parte de su condición humana. Reconocen que en algún grado, cada uno es un prisionero de su pasado. Mientras profundizan su compresión de las dificultades que entrañan todas las relaciones humanas, también aprenden a apreciar sus momentos de intimidad duramente ganados.

La comunidad con otras personas incluye todos los significados de la palabra común. Eso significa pertenecer a una sociedad, tener un rol público, ser parte de lo que es universal. Significa tener un sentimiento de familiaridad, de ser conocido, de comulgar con otros. Significa tomar parte en las costumbres, frecuentar los lugares comunes, lo ordinario, el día a día. También conlleva un sentimiento de pequeñez, de insignificancia, la percepción de que los problemas de uno son «como una gota de lluvia en el océano". Los sobrevivientes que han recuperado el sentido de pertenencia a una comunidad pueden descansar de sus labores. Su recuperación ha sido lograda; todo lo que les queda al frente es su vida.

\section{REFERENCIAS}

Herman, J. (1997). Trauma y recuperación. Madrid: Espasa.

Morales Miranda, C. (2007). Trauma psíquico y trastorno de estrés post-traumático. Lima, Perú, Universidad Femenina del Sagrado Corazón: Ediciones Libro Amigo. 